\title{
Embolization of Type 2 Endoleaks in the Abdominal Aorta Using Ethylene Vinyl Alcohol Copolymer
}

\section{Embolisation von Typ-2-Endoleaks der Bauchaorta mit Ethylen-Vinylalkohol-Copolymer}

Authors

Claus Nolte-Ernsting ${ }^{1}$, Frank-Peter Mecklenbeck ${ }^{1}$, Alexander Stehr ${ }^{2}$

Affiliations

1 Klinik für Diagnostische und Interventionelle Radiologie, Evangelisches Krankenhaus Mülheim an der Ruhr, Mülheim an der Ruhr, Germany

2 Gefäßchirurgische Klinik, Evangelisches Krankenhaus Mülheim an der Ruhr, Germany

Key words

aortic aneurysm, endoleak, embolization, ethylene vinyl alcohol copolymer

received 03.02.2021

accepted 26.04.2021

published online 17.06.2021

Bibliography

Fortschr Röntgenstr 2021; 193: 1426-1435

DOI 10.1055/a-1502-7883

ISSN 1438-9029

(C) 2021. Thieme. All rights reserved.

Georg Thieme Verlag KG, Rüdigerstraße 14,

70469 Stuttgart, Germany

Correspondence

Prof. Claus Nolte-Ernsting

Klinik für Diagnostische und Interventionelle Radiologie,

Evangelisches Krankenhaus Mülheim, Wertgasse 30,

45468 Mülheim an der Ruhr, Germany

Tel.: $+49 / 2$ 08/3092701

Fax: $+49 / 2$ 08/30927 25

Claus.Nolte-Ernsting@evkmh.de

\section{ABSTRACT}

Background Type 2 endoleaks (T2EL) are the most frequent complication following endovascular aortic repair. Multiple studies primarily deal with the technical and clinical success of the embolization of persisting T2EL, thereby revealing controversial outcomes. Current reports rarely focus on the detailed execution of such a complex interventional procedure with respect to the difficult anatomic setting.

Methods The present review provides an in-depth depiction and evaluation of the interventional methodology of the embolization of T2EL in the abdominal aorta with use of ethylene vinyl alcohol copolymer (EVOH). Complicating anatomic conditions are taken into account as well as technical and clinical success rates.

Results Using the transarterial approach, there are at least 4 different pathways to access the nidus of a T2EL. CT-guided direct puncture of the aneurysm sac provides an alternative method of high technical success. EVOH with its slow solidification characteristics enables good control to achieve complete filling of the T2EL. During the intervention, however, it remains difficult to meet exactly the embolization endpoint, especially in large T2ELs.

Conclusion T2EL embolization using EVOH is an effective treatment with low major complication rates when conducted by skilled interventionists with detailed knowledge of diverse complex access routes.

\section{Key Points:}

- Many roads lead to Rome to access the nidus of a T2EL including diverse complex transarterial pathways and direct aneurysm sac puncture.

- Ethylene vinyl alcohol co-polymer enables good control for slow filling of the nidus with low risk of major complications.

- Identification of the embolization endpoint remains difficult during the procedure and may result in secondary interventions.

- Successful T2EL embolization requires detailed knowledge of all access routes to the nidus and skilled handling of liquid embolics.

\section{Citation Format}

- Nolte-Ernsting C, Mecklenbeck F, Stehr A. Embolization of Type 2 Endoleaks in the Abdominal Aorta Using Ethylene Vinyl Alcohol Copolymer. Fortschr Röntgenstr 2021; 193 : 1426-1435

\section{ZUSAMMENFASSUNG}

Hintergrund Typ-2-Endoleaks (T2EL) stellen die häufigste Komplikation nach endovaskulärer Implantation einer aortoiliakalen Prothese dar. Es existieren zahlreiche Studien überwiegend zu technischen und klinischen Erfolgen der Embolisation von persistierenden T2EL mit kontroversen Ergebnissen. Jedoch finden sich nur wenige Berichte zum detaillierten Ablauf dieser komplexen interventionellen Prozedur in schwieriger anatomischer Umgebung. 
Methode Die vorliegende Übersichtsarbeit legt den Schwerpunkt auf die ausführliche methodische Darstellung und Bewertung des interventionellen Vorgehens bei der Embolisation von T2EL in der Bauchaorta unter Berücksichtigung der komplizierten anatomischen Gegebenheiten sowie der technischen und klinischen Erfolgsraten. Als Flüssigembolisat wird Ethylen-Vinylalkohol-Copolymer (EVOH) verwendet.

Ergebnisse Bei transarteriellem Vorgehen existieren mindestens 4 verschiedene Zugangsmöglichkeiten zum Nidus des T2EL. Alternativ empfiehlt sich eine CT-gesteuerte Direkt- punktion des Aneurysmasacks als Methode mit hoher technischer Erfolgsquote. EVOH ermöglicht aufgrund seiner langsamen Aushärtung eine gute Kontrolle, um das Ziel der kompletten Auffüllung des T2EL zu erreichen. Während der Intervention ist es jedoch schwierig, den Embolisationsendpunkt exakt zu treffen, insbesondere bei großen T2EL.

Schlussfolgerung Die Embolisation von T2EL mit EVOH stellt in der Hand erfahrener Interventionalisten mit detaillierten Kenntnissen über diverse komplizierte Zugangsmöglichkeiten eine effektive und komplikationsarme Behandlung dar.

\section{Introduction}

Type 2 endoleaks (T2EL) are caused by the retrograde flow of blood via aortic branches into an aneurysm sac that has been treated by an endovascular aortic stent graft (endovascular aortic repair, EVAR) with intact fixation and lining [1]. In a meta-analysis including over 36000 cases, the pooled T2EL prevalence is $22 \%$ [2]. Does every T2EL need to be embolized? Based on current knowledge, the answer is absolutely not since approximately $50 \%$ of T2ELs thrombose spontaneously within the first weeks and months after EVAR $[1,3]$. In particular, the number and diameter $(>2.5 \mathrm{~mm})$ of patent aortic branches, usually the lumbar arteries and the inferior mesenteric artery (IMA), are considered predictors for the persistence of a T2EL. There are no standardized treatment recommendations for T2ELs that do not regress. The spectrum ranges from conservative to aggressive. In the guidelines provided by the professional societies, treatment of persistent T2ELs is only recommended in the case of an increase in aneurysm diameter [1, 9-11]. Growth of an aneurysm $>5 \mathrm{~mm}$ in 6-12 months is used as a cut-off value for the indication of T2EL embolization in numerous current publications $[1,12-18]$. Aneurysm rupture is rare in the case of T2ELs but absolutely must be prevented due to the high mortality rate. The percentage of interventions performed due to a T2EL within 5 years is $22 \%$ [19]. The indication for T2EL embolization should be determined on an interdisciplinary basis by a vascular board. If treatment is needed, many roads lead to Rome. There are two established ways of accessing the endoleak cavity: transarterial catheterization with a microcatheter and percutaneous direct puncture of the aneurysm sac. Performing T2EL coil embolization alone is often ineffective due to the high recanalization rates [20-22]. The liquid embolic agents used most frequently in T2ELs are N-butylcyanoacrylate (NBCA) and ethylene vinyl alcohol copolymer (EVOH). The current results achieved with NBCA in T2ELs are sobering with recurrence rates of up to $71 \%$ even in combination with coils [22, 23]. EVOH is increasingly used for T2EL treatment [24]. $\mathrm{EVOH}$ is significantly more expensive than NBCA but provides a number of advantages, particularly with regard to endoleak embolization. The main focus of the present overview regarding T2EL embolization is the practical interventional approach using $\mathrm{EVOH}$. Our main goal is to explain and evaluate numerous procedural details to be taken into consideration for complex embolization of a difficult anatomy.

\section{Anatomical features of T2ELs}

The intraaortic cavity of an endoleak is referred to as the nidus. The nidus acts as a distribution station and is connected to the afferent and efferent feeding arteries of the T2EL ( $>$ Fig. 1). In principle, all branches of the abdominal aorta can act as inflow or outflow arteries. Infrarenal involvement is most commonly seen in the IMA and lumbar arteries L4 and L3 as well as the median sacral artery (MSA), accessory renal arteries, and the testicular or ovarian artery. A lumbar artery pair often has a common aortic origin and at the level of L4 may also share an origin with the MSA ( Fig. 1). A T2EL can even be fed by the vasa vasorum of the aortic wall [25]. Moreover, it is possible for the aneurysm sac to have more than one nidus, each with its own separate supply [13]. Furthermore, accessory renal arteries can act as a strong trigger for the formation and persistence of an endoleak. For this to occur, an accessory renal artery must arise from the aneurysm sac and not be covered by a wall of the aortic stent graft. In this context, the accessory renal artery always functions as an outlet vessel for the endoleak. CT/MRI shows characteristic contrast dynamics in the dependent renal parenchyma ( $\triangleright$ Fig. 2).

\section{Intervention objective}

The goal of T2EL treatment is to stop flow within the endoleak cavity and to relieve pressure in the aneurysm sac. For technical success of the intervention, the embolization endpoint includes filling of the nidus with an embolic agent with all involved branches ideally being blocked [17, 26, 27]. Clinical success has been achieved when the aneurysm remains stable or shrinks in postinterventional follow-up. However, this does not fundamentally rule out the persistence of a small residual T2EL [26].

\section{EVOH as a liquid embolic agent for T2EL}

EVOH (Onyx; ev3/Medtronic, USA) is provided with the solution dimethyl sulfoxide (DMSO) and can be effectively visualized via fluoroscopy with the addition of tantalum powder. EVOH is available with various levels of viscosity: Onyx 18 (6\% EVOH), Onyx 20 (6.5\% EVOH) and the more viscous Onyx 34 (8\% EVOH). Immediately prior to use, $\mathrm{EVOH}$ is prepared for at least 20 minutes in a shaker. EVOH must be injected using a DMSO-compatible micro- 
- Table 1 Examples of interventional devices utilized in our institution especially for embolization of T2EL.

\begin{tabular}{|c|c|c|c|c|c|}
\hline position & product & name & caliber & length & manufacturer \\
\hline 1 & Catheter & Non-taper Angle Type T90 & $5-\mathrm{F}$ & $65 \mathrm{~cm}$ & Terumo Europe, Belgium \\
\hline 2 & Microcatheter & Rebar-18 & $2.4-\mathrm{F}$ & $153 \mathrm{~cm}$ & ev3/Medtronic, USA \\
\hline 3 & Microcatheter & Echelon-14 & 1.9-F & $150 \mathrm{~cm}$ & ev3/Medtronic, USA \\
\hline 4 & Microcatheter & Apollo & $1.5-\mathrm{F}$ & $165 \mathrm{~cm}$ & ev3/Medtronic, USA \\
\hline 5 & Guidewire & Radifocus Guide Wire M & 0.032-inch & $150 \mathrm{~cm}$ & Terumo Europe, Belgium \\
\hline 6 & Guidewire & Radifocus Guide Wire M & 0.016 -inch & $150 \mathrm{~cm}$ & Terumo Europe, Belgium \\
\hline 7 & Guidewire & Fathom-14 & 0.014-inch & $200 \mathrm{~cm}$ & Boston Scientific, USA \\
\hline 8 & Guidewire & Transend & 0.014-inch & $190 \mathrm{~cm}$ & Boston Scientific, USA \\
\hline 9 & Guidewire & Mirage & 0.008 -inch & $200 \mathrm{~cm}$ & ev3/Medtronic, USA \\
\hline 10 & Puncture needle & $\begin{array}{l}\text { Kellett Drainage Access } \\
\text { Catheter Needle }\end{array}$ & $19-G / 5-F$ & $20 \mathrm{~cm}$ & Cook, USA \\
\hline 11 & Microcoil & Figure $8-18$ & 0.018-inch & $2 \times 5 \mathrm{~mm}$ & Boston Scientific, USA \\
\hline
\end{tabular}

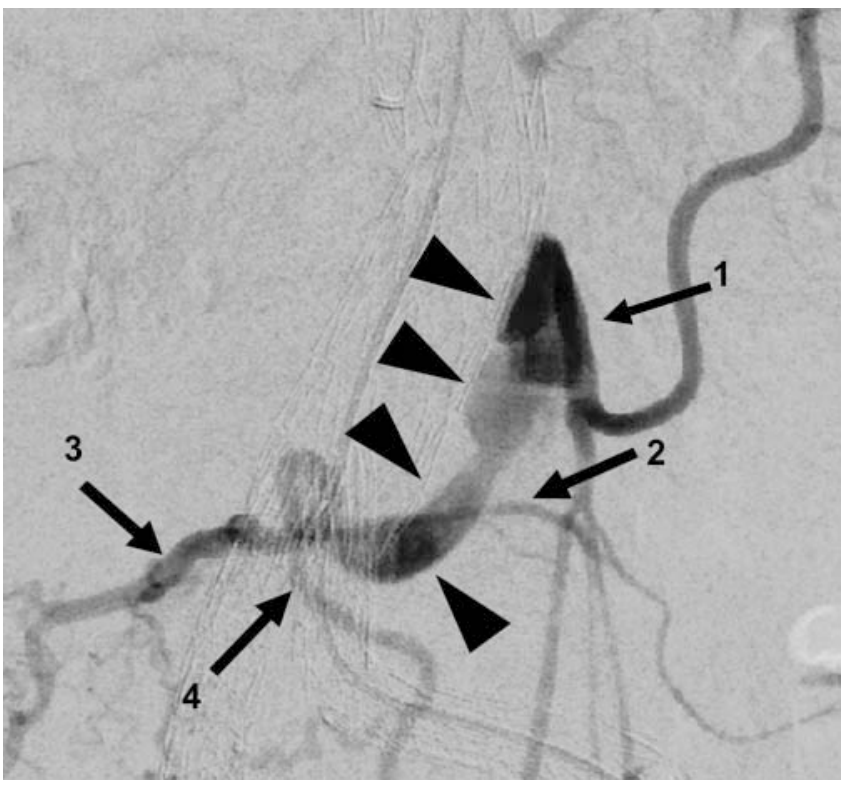

- Fig. 1 Angiographic aspect of the nidus of a T2EL (arrowheads). Visible feeding vessels are the inferior mesenteric artery (1), the left (2) and right (3) L4 lumbar arteries, and the median sacral artery (4). Both L4 arteries and the MSA have a common aortic origin.

catheter ( $\triangleright$ Table 1 ) whose dead space volume must be filled with DMSO prior to the first application [28, 29]. In contrast to NBCA, $\mathrm{EVOH}$ is not adhesive and does not harden within several seconds of injection. For T2EL embolization, EVOH provides the significant advantage that solidification takes place slowly over about 5 minutes from the outside to the inside, thus allowing controlled distribution of the embolic agent in the target region [28, 29]. An EVOH cast gradually forms. Use of a microcatheter with a detachable tip allows removal from the hardened EVOH cast ( $\triangleright$ Table 1, no. 4).
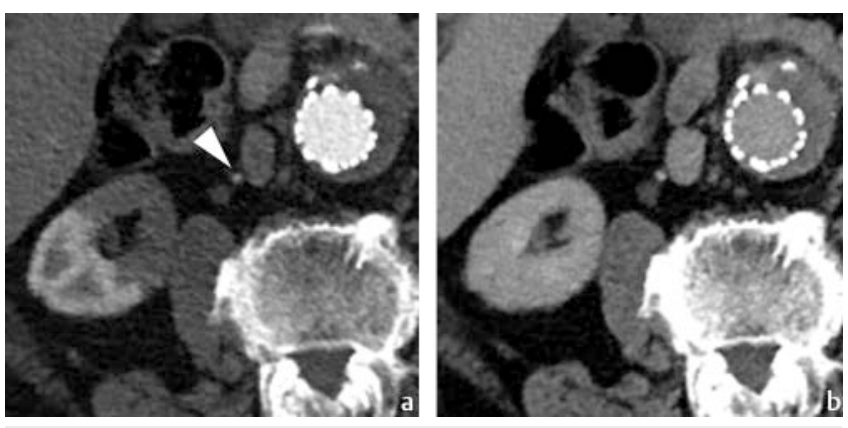

- Fig. 2 CT of an 86-year-old male patient with a T2EL. a Renal influx of contrast agent through an accessory renal artery (arrowhead) arising from a T2EL is typically delayed, resulting in a characteristic enhancement pattern that simulates segmental renal infarction in the early phase. $\mathbf{b}$ Only in the late phase, the corresponding parenchymal contrast enhancement levels out.

Pronounced local injection pain caused by the DMSO is characteristic when using EVOH. For example, pain occurs when some of the embolic agent escapes the aneurysm sac via lumbar branches. After a brief injection pause, the pain quickly abates. Use of an IV analgesic is helpful. Short-term anesthesia is rarely necessary. A further peculiarity is that metabolites of DMSO cause a garlic-like mouth and body odor for approximately 2 days [28, 29].

The conventional Onyx formulations listed above are highly radiopaque due to their tantalum content and cause significant artifacts on CT images that greatly limit the assessment of aneurysms [29, 30]. A further development by the manufacturer includes a lower tantalum concentration (Onyx 34 L LES), resulting in fewer image artifacts [30]. In contrast to CT, EVOH results in hardly any image artifacts on ultrasound and MRI. MRI is significantly more sensitive than CT for endoleak diagnosis [31]. As such, MRI is also suitable for follow-up after embolization with $\mathrm{EVOH}$ as long as the stent graft is MR-compatible. Contrast-enhanced ultrasound (CEUS) is also often used for diagnosing T2ELs. A meta-analysis could not find any diagnostic disadvanta- 

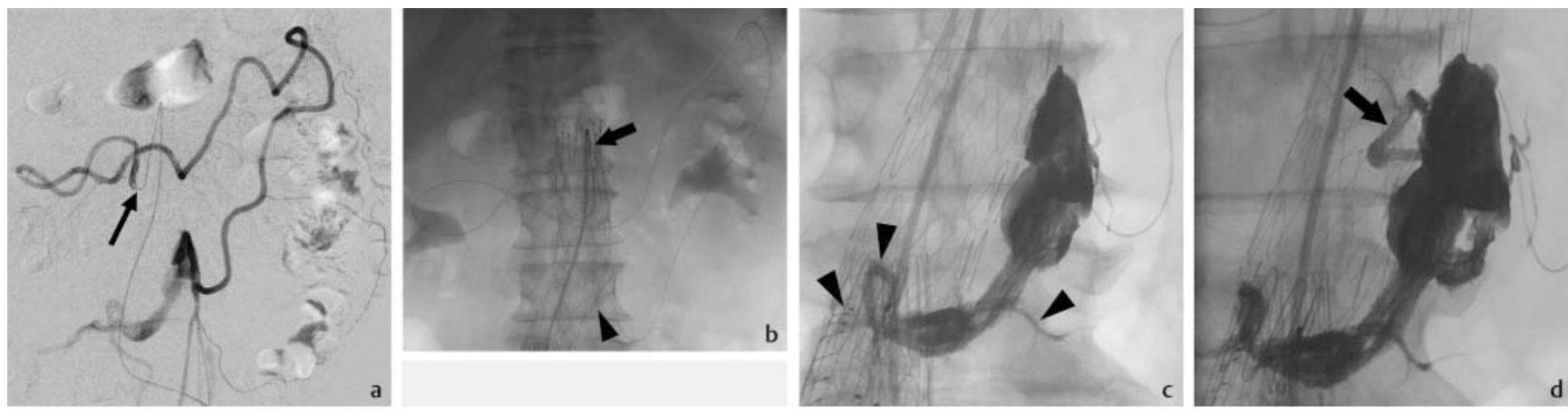

- Fig. 3 Transarterial access to a T2EL in a 59-year-old male patient via the SMA route - middle colic artery - anastomosis of Riolan - left colic artery - IMA. a A 5-F glide catheter with a rectangular tip is placed in the orifice of the middle colic artery (arrow). b A coil-reinforced 5-F sheath in the origin of the superior mesenteric artery (arrow) stabilizes catheterization through the complex vasculature. The microwire has already accessed the T2EL (arrowhead). c Filling of the nidus as well as feeding arteries visible on angiography (arrowheads) with EVOH. Is this the embolization endpoint? $\mathbf{d}$ No, because further injection of $\mathrm{EVOH}$ leads to unexpected distribution also into the left L3-artery (arrow), acting as inflow vessel together with the IMA.

ges of CEUS compared to CT. However, this analysis did not include data after EVOH embolization [32].

Alternative liquid embolic agents (Squid peri; Emboflu, Switzerland/Phil; Microvention, USA) with similar or optimized characteristics regarding application and imaging are now available. However, the available data regarding T2EL is still very limited. All of our experience with T2EL embolization is based on the use of Onyx.

It is important to mention that all modern liquid embolic agents are expensive. Moreover, the use of EVOH in the aortic lumen is considered "off label" for some products and this must be taken into consideration in the informed consent discussion.

\section{T2EL access pathways}

\section{Transarterial access}

CT angiography performed in advance identifies the feeding arteries of the T2EL and is helpful for initial planning of an access pathway to the endoleak. The intervention is usually performed under local anesthesia via a transfemoral 4-F or 5-F introducer sheath. There are four potential arteries for accessing the aneurysm sac: the IMA, the L4 lumbar arteries on both sides, and the MSA. Superselective catheterization of lumbar arteries above L4 is not possible in most cases. Microcatheters are inserted coaxially via an external guide catheter with an inner lumen of 0.038 inches. We use 1.5-F to 2.4-F microcatheters and guidewires with a diameter of $0.008-0.016$ inches ( $\triangleright$ Table 1 ). Depending on the length of the external catheter and also in the case of a long transarterial catheterization path ( $\triangleright$ Fig. 3 ), a microcatheter length of at least $150 \mathrm{~cm}$ should be selected. Selective intraarterial spasmolysis, e. g., with glycerol nitrate, prior to the start of catheterization is recommended. During catheterization with the microcatheter, the pathway to the endoleak is visualized again via angiography. There may be no contrast enhancement of the nidus particularly when the pathway to the endoleak utilizes an efferent branch. a) Access to the inferior mesenteric artery:

Catheterization is performed via the superior mesenteric artery into the middle colic artery, then through the anastomosis of Riolan into the left colic artery and from there into the IMA

( $\vee$ Fig. 3). Due to the length of the pathway, it is helpful to use a long coil-reinforced sheath whose tip can be inserted up to or into the origin of the super mesenteric artery. To catheterize the origin of the middle colic artery, we prefer to use a $5-\mathrm{F}$ glide catheter with a short tip with a 90-degree angle ( $\vee$ Table 1, no. 1). If the angled catheter can be replaced with a straight 4-F glide catheter in the middle colic artery in the next step, better coaxial advancement of the microcatheter into the IMA can be achieved.

b) Access via the lumbar arteries:

The L4 lumbar arteries can be accessed via the internal iliac artery on the same side. The iliolumbar artery provides an important anastomosis between the internal iliac artery and the $L 4$ artery for catheterization with the microcatheter. The iliolumbar artery can usually be evaluated on initial CT ( $\triangleright$ Fig. 4). Therefore, the suitable side for access to the endoleak can be determined in advance. Due to the aortobiiliac stent graft, crossover access to the internal iliac artery is not possible. For ipsilateral catheterization of the internal iliac artery, we also use a 5-F glide catheter with a short rectangular tip. The soft glide catheter can be inserted preferably via a 0.032-inch hydrophilic guidewire ( $\vee$ Table 1 ) without tension into the internal iliac artery and from there placed in the origin of the iliolumbar artery ( $\triangleright$ Fig. 5). The subsequent coaxial catheterization with the microcatheter into the nidus is often time intensive. Under angiographic control and intraarterial spasmolysis, the microcatheter is gradually advanced through the lumbar branch of the iliolumbar artery and a small-caliber rete into the L4 artery ( $\triangleright$ Fig. 5 ). Different microwires must sometimes be used on the way to the target ( $\triangleright$ Table 1 ). If catheterization via the iliolumbar artery is not possible, an alternative route via the deep circumflex iliac artery can allow access to the $\mathrm{L} 4$ artery in individual cases ( $\triangleright$ Fig. $\mathbf{6}$ ). 


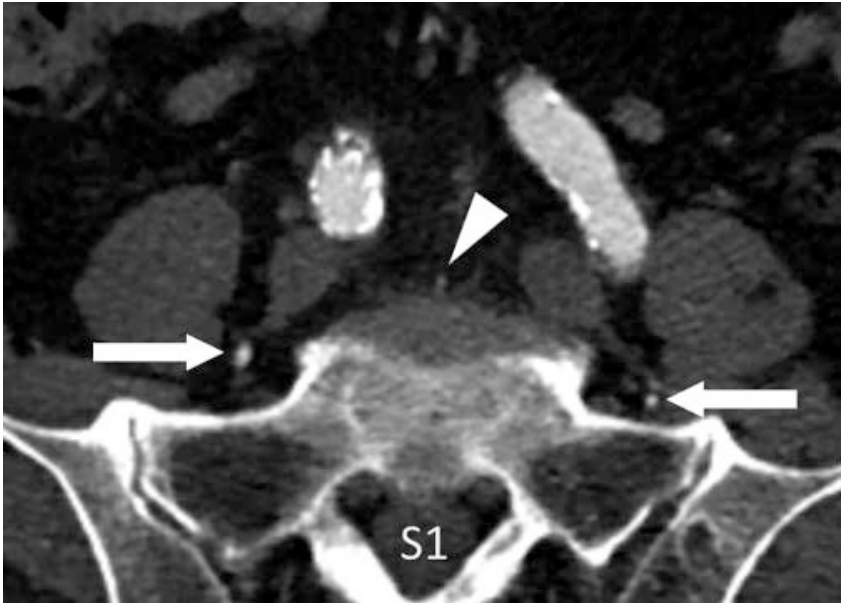

- Fig. 4 Typical locations of the lumbar branches of both iliolumbar arteries (arrows) and the median sacral artery (arrowhead) as demonstrated by CT. c) Access to the median sacral artery:

Whether the MSA is suitable for accessing the endoleak can also be evaluated based on the initial CT scan ( $\triangleright$ Fig. 4). The MSA is fed on both sides by multiple transverse anastomoses from the internal iliac artery. Angiography often shows the pathway to the endoleak via the MSA as a hairpin curve

( $\triangleright$ Fig. 7). Catheterization is difficult but is basically performed as described under $b$ ).

Occasionally, it is necessary during the intervention to catheterize different arterial accesses, possibly with puncture of the femoral arteries on both sides.

\section{Direct percutaneous puncture}

Direct percutaneous puncture of the aneurysm sac with a fine needle can be performed with high precision under contrast-enhanced CT imaging guidance. The use of sonographic or fluoroscopic puncture is less established. The nidus is not always easily
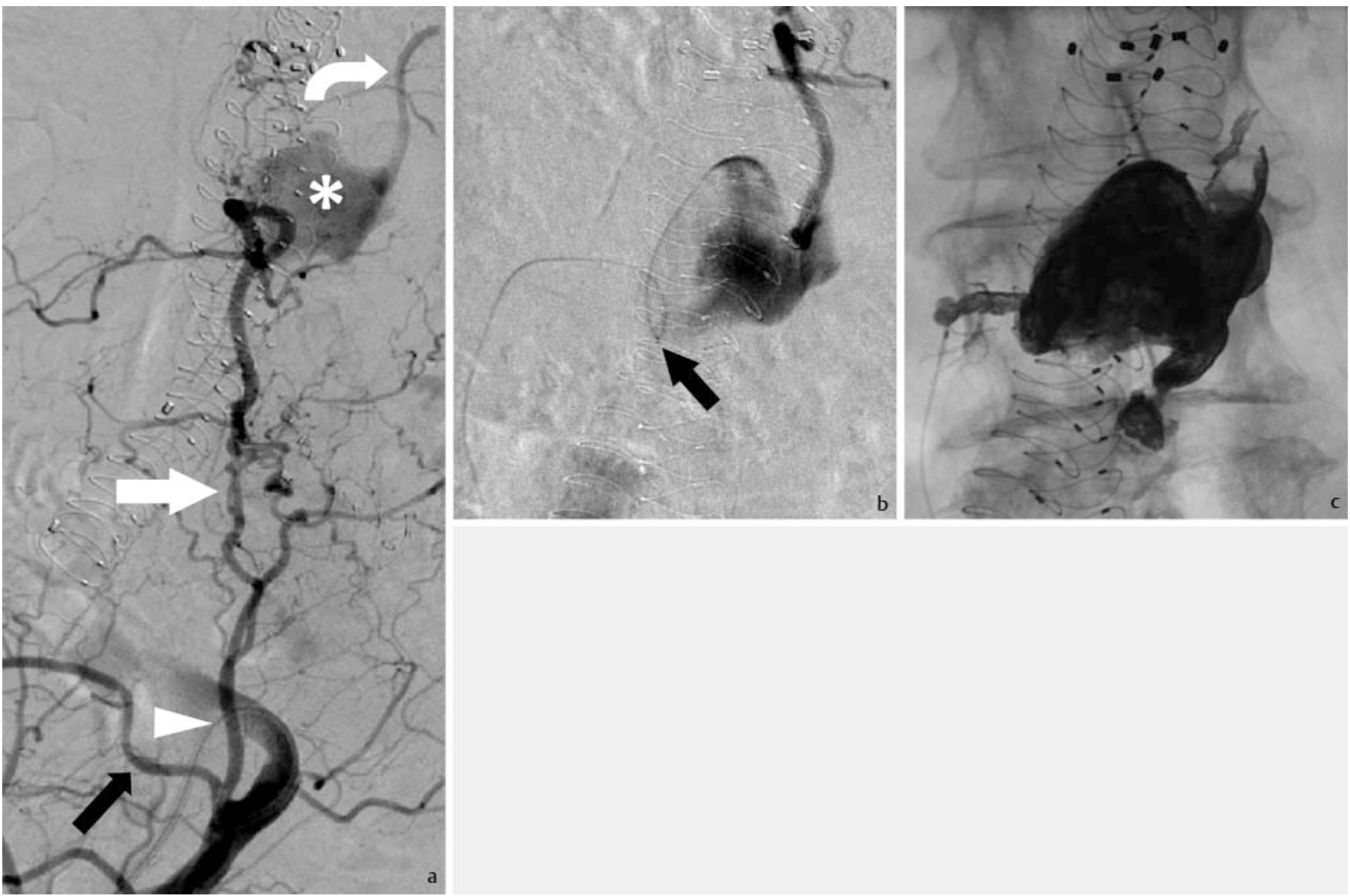

- Fig. 5 Transarterial access to a T2EL via the right iliolumbar artery in a 72-year-old female patient. a Angiography (LAO $20^{\circ}$ ) demonstrates a T2EL (asterisk) and a draining left lumbar artery (curved arrow). The iliolumbar artery usually bifurcates into an iliac branch (black arrow) and a lumbar branch. The latter communicates with the L4-artery mostly via an interposed tortuous rete which is difficult to catheterize (white arrow). $\mathbf{b}$ In front of the aortic orifice, the lumbar artery often loops (arrow), thus building another barrier shortly before access to the nidus. c Final EVOH cast consists of $9 \mathrm{ml}$ of Onyx. 

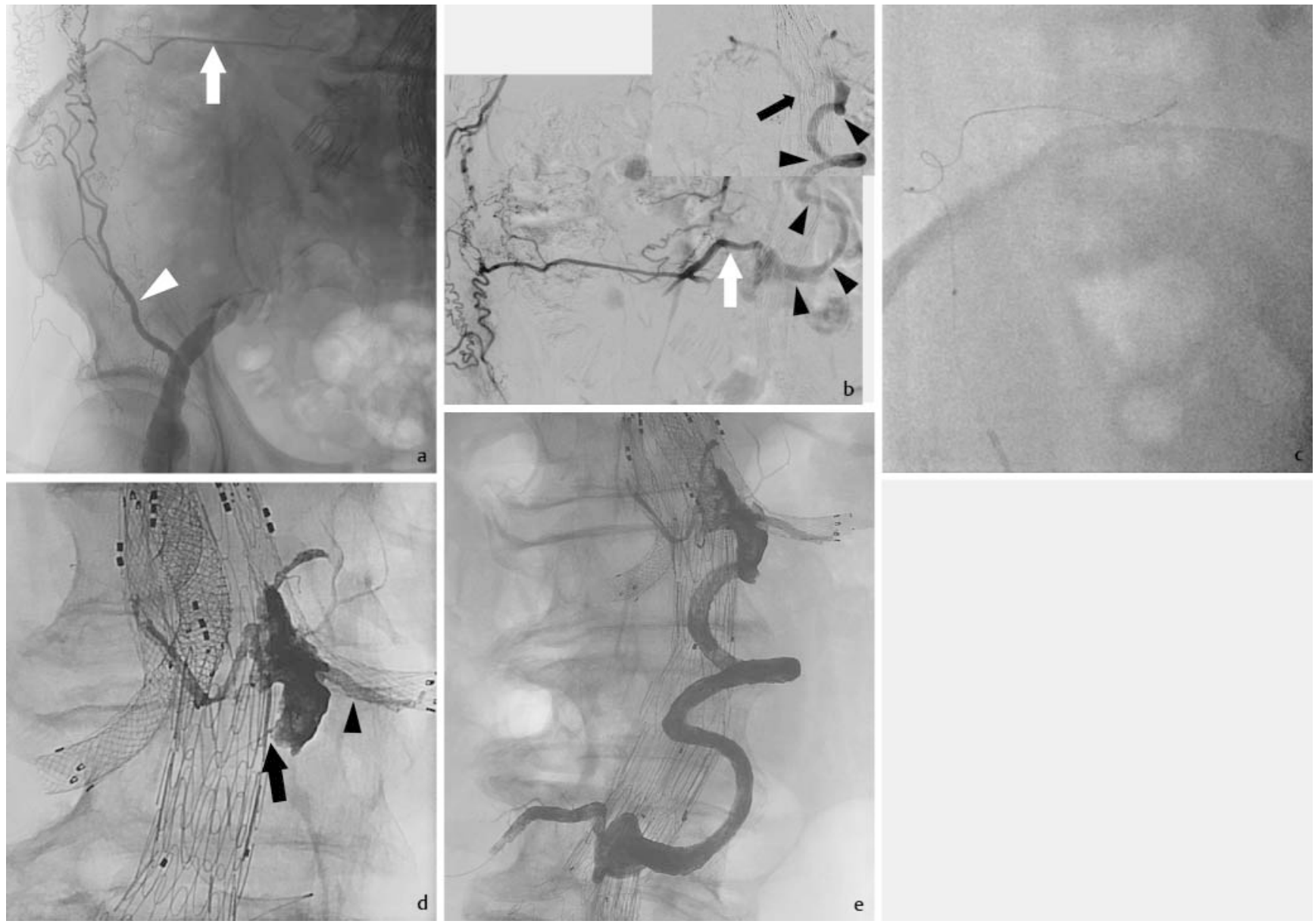

- Fig. 6 a Uncommon route in a 77-year-old patient to access the T2EL via the right deep circumflex iliac artery (arrowhead) alongside the iliac crest (arrow). b Anastomosis with the L4-artery (white arrow) followed by a helical nidus (arrowheads) communicating with 3 outflow arteries at the level of L1 (black arrow). c Catheterization of the tortuous vessel anatomy using a 0.008 -inch microwire is especially challenging. $\mathbf{d}$ The microcatheter is advanced to the superior margin of the T2EL (arrow). The first EVOH injection creeps into both L1-arteries and into an accessory renal artery on the left (arrowhead). e Using stepwise catheter pullback, the nidus is gradually filled completely with 11 ml on Onyx administered within $60 \mathrm{~min}$.

accessible from the outside, primarily when the aneurysm sac is surrounded by organs that protect it. Depending on the anatomical situation, direct puncture is performed via a translumbar approach in a prone position or more rarely transabdominally in a supine position. The goal is to position the tip of the puncture needle safely within the nidus but not in the aneurysm sac thrombus ( $\triangleright$ Fig. 8). For puncture of the aortic wall, we prefer a 19-G coaxial needle with a $20-\mathrm{cm}$ long $5-\mathrm{F}$ plastic catheter ( $\vee$ Table 1 , no. 10). Spontaneous escape of blood via the puncture needle indicates that it has been successfully placed in the nidus. The 5-F plastic catheter is inserted into the nidus under $\mathrm{CT}$ guidance via a 0.035 -inch guidewire. The subsequent intervention steps are performed under angiographic guidance. A standard introducer sheath is initially inserted via a retroperitoneal approach up to the aortic wall and is sutured to the skin. The sheath makes it possible to exchange selective catheters (e. g., Judkins R) in the aneurysm sac for catheterization of the nidus in different directions. This ensures that the microcatheter can be directed into the corners of the endoleak cavity under fluoroscopic guidance even in the case of complex T2ELs ( $\triangleright$ Fig. 8). For movement of the catheter within the aneurysm sac, knowledge of the puncture site in the aortic wall provides orientation so that access to the aneurysm sac is not lost. So that the puncture site is visible on fluoroscopy, we place a single coil ( $\triangleright$ Table 1 ) via the puncture needle directly on the exterior of the aortic wall during CT puncture ( $\triangleright$ Fig.9).

A disadvantage of direct puncture is that the patient must be transported with established percutaneous aortic access from the CT unit to the cath lab. Therefore, the use of anesthesia is recommended. Alternatives that do not require complicated patient transfer are hybrid CT/C-arm combinations and modern angiography systems with a rotating C-arm and an integrated "cone beam" CT option [33, 34].

For the sake of completeness, alternative but rarely indicated pathways to the endoleak are mentioned here: Transcaval access [35-37], peri- and transgraft access [38, 39], and transosseous access [40]. 

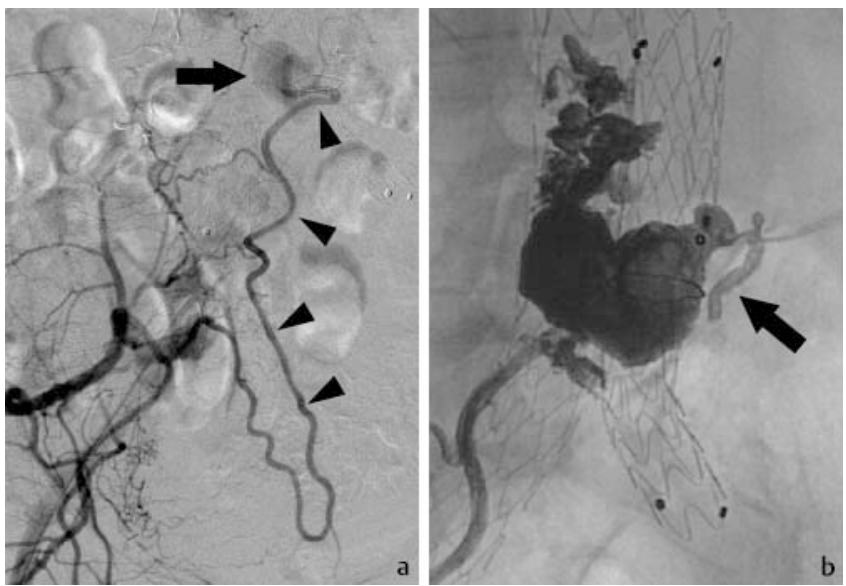

- Fig. 7 Transarterial access to a T2EL via the MSA in a 76-year-old female patient. A prior embolization attempt via the iliolumbar artery did not include the nidus. a Angiography of the right internal iliac artery demonstrates a hairpin-curve-like anastomosis with the MSA (arrowheads) feeding the T2EL (arrow). b After injection of $9 \mathrm{ml}$ of Onyx into the nidus, $\mathrm{EVOH}$ also drifts into the origin of the IMA (arrow)

\section{Application of EVOH in T2EL}

Reaching the endoleak is the first step in the successful fluoroscopic application of the embolic agent EVOH. To fill the T2EL as completely as possible with $\mathrm{EVOH}$, it is advisable to initially insert the microcatheter deep into the nidus and to begin with $\mathrm{EVOH}$ application at the periphery ( $\vee$ Fig. $\mathbf{6 , 8}$ ). As the cast slowly grows, the tip of the microcatheter is incrementally withdrawn and the nidus is gradually filled. In the case of distribution of EVOH in an undesired direction, injection can be paused to promote EVOH distribution in a different direction after partial solidification. As the EVOH cast grows, the tip of the microcatheter is sometimes difficult to identify, and in the case of a large nidus, EVOH application often takes more than 1 hour. In reality, it is often difficult to identify whether the embolization endpoint can be optimally met during the procedure. This is especially true for large T2ELs. The only fluoroscopic indication of effective filling of the nidus is slow controlled penetration of EVOH into the origins of the relevant branches ( $\triangleright$ Fig. $\mathbf{3 c}, \mathbf{d}$ ). Moreover, using the direct puncture technique, a final EVOH injection into the puncture site marked by the coil on the aortic wall can be performed.

In the case of the transarterial approach, it is not always possible to place the microcatheter in the nidus. Then it makes sense, but in our experience is less effective, to attempt to push $\mathrm{EVOH}$ from outside of the aneurysm sac through a feeding artery into the nidus. The "plug and push" technique developed by Wohlgemuth et al. using the less viscous Onyx 18 is suitable for this purpose $[27,29]$. Embolization of only the individual feeding branches but not the nidus is never sufficient.

EVOH can be used as a single embolic agent [26] or in combination with coils [41, 42]. It must be taken into consideration that coils can no longer pass through the microcatheter after contact with $\mathrm{EVOH}$. Microcoils with a diameter of 2-5 mm are suitable for closing T2EL branches with maximum precision ( $\mathbf{F i g . 8}$ ).
However, catheterization of all vascular branches with a microcatheter from the lumen of the endoleak often cannot be achieved. In the case of endoleaks with a large volume, it can be helpful to line the nidus with volume coils to reduce the amount of $\mathrm{EVOH}$.

\section{Technical and clinical results achieved with $\mathrm{EVOH}$}

A meta-analysis by Jamieson et al. [24] provides an overview of 12 smaller studies with a total of 174 patients. However, the endoleaks in 21 cases were not T2ELs but rather type 1 or type 3 endoleaks. The average technical success rate in the evaluated studies was $96 \%$ for monotherapy with EVOH [24]. Technical success was defined as the lack of evidence of a residual endoleak on the final angiogram. In our opinion, regardless of the embolic agent that is used, it is difficult to evaluate technical success during the procedure and is hardly possible based solely on the final angiography examination. Whether embolization was successful should be determined directly after the intervention via ultrasound or contrast-enhanced MRI in the case of EVOH.

The meta-analysis by Jamieson et al. specified a clinical success rate for EVOH monoembolization of $79 \%$ [24]. However, the definition of clinical success was not uniform and included the lack of evidence of a residual endoleak and/or the detection of a stable or regressive aneurysm diameter on follow-up CT imaging [24]. Similar clinical success rates for T2EL were also found in later studies with $\mathrm{EVOH}$ being used alone or in combination with coils $[17,26$, $27,43]$. On a retrospective basis, technically incomplete embolization of T2ELs with EVOH does not necessarily rule out clinical success [26]. On a prospective basis, one should however assume that more complete initial T2EL embolization results in more lasting clinical success.

The embolization results published for NBCA without/with coils in T2ELs [21-23, 44] tend to be inferior to the EVOH data. Horinouchi et al. currently report clinical success rates with $\mathrm{NBCH}$ and coils of $73 \%$ and $32 \%$ after 1 or 3 years, respectively [22].

In total, the published success rates show that a not insignificant number of T2ELs persist or recur in spite of embolization. In our opinion, a main reason for the lack of embolization success is that the embolization endpoint cannot be precisely detected via fluoroscopy. There can also be more than 1 nidus each with separate perfusion, but with only one of them having been successfully embolized. Moreover, occult type 1 and type 3 endoleaks can even be the reason for embolization failure [45]. After initial embolization, subsequent interventions are often necessary in the case of continued aneurysm growth. However, it is unclear whether second embolization procedures with EVOH actually achieve the desired long-term success [26]. Additional study results are needed here. 

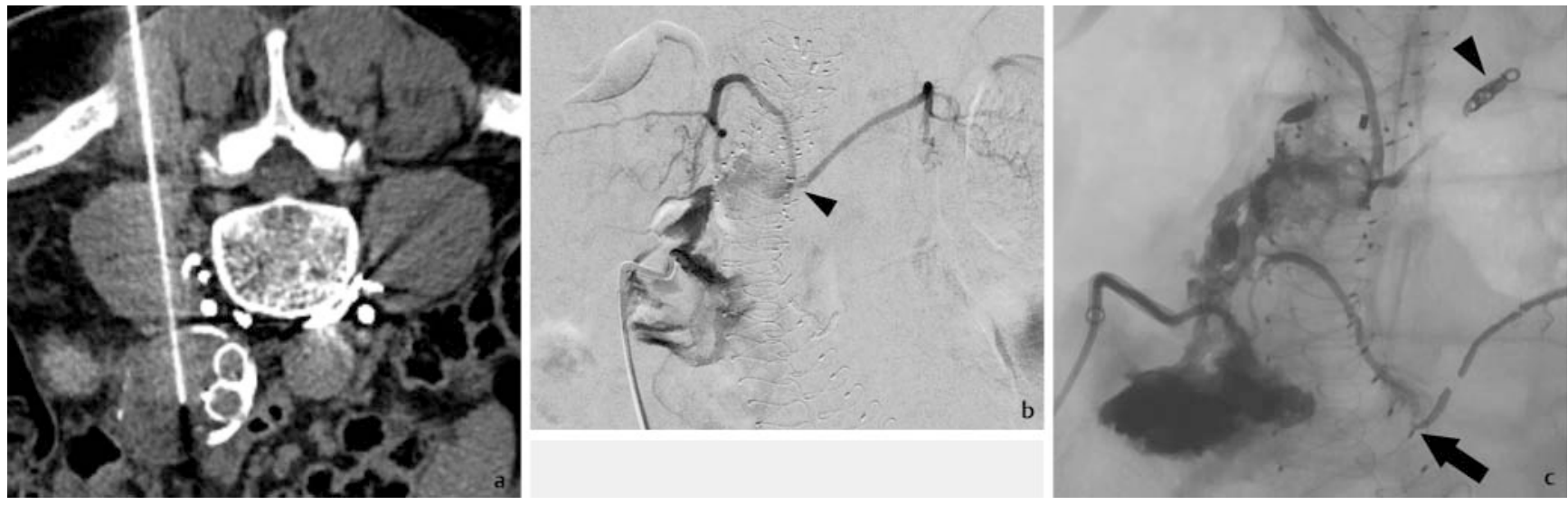

- Fig. 8 a CT-guided direct puncture of a T2EL in an 83-year-old male patient. 9 months before, transarterial embolization of both L4-arteries failed to reach the nidus. $\mathbf{b}$ Angiography of the endoleak cavity is conducted via a catheter introduced into the aneurysm sac. Both L3-arteries arise from a common orifice and act as outflow vessels (arrowhead). c At first, coil embolization of the left L3-artery is performed, and then, the right L3-artery is occluded by EVOH. A total of $13.5 \mathrm{ml}$ of Onyx is injected into the nidus. Note that both previously embolized L4-arteries are not connected to the nidus (arrow).
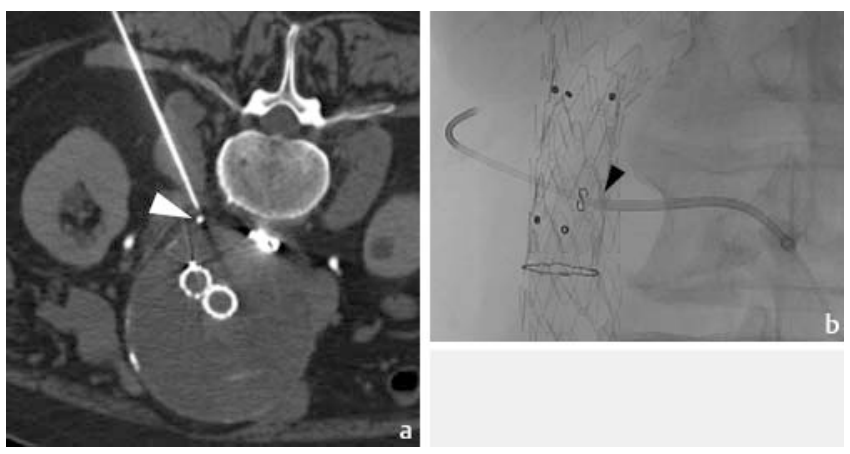

- Fig. 9 a CT-guided labelling of the puncture site in the aortic wall with a single 2-mm microcoil (arrowhead) placed at the exterior aspect. b Subsequently, the labelled puncture site can be identified in all fluoroscopic planes. The tip of the sheath is located outside the aneurysm sac (arrowhead).

\section{Which access pathway is better?}

To date, transarterial embolization has been used in the majority of published studies. An advantage of a transarterial approach is that the aortic wall does not need to be penetrated, which suggests a (not yet proven) lower procedural risk than direct puncture. A current meta-analysis includes 9 studies that address the comparison of transarterial techniques $(n=259)$ versus direct puncture $(n=190)$ using diverse embolic agents [46]. The authors of the meta-analysis determined a significantly higher technical success rate for direct puncture ( $98.7 \%$ versus $84.0 \%$ ), while no significant difference regarding clinical success and complication rate was determined [46]. The technical inferiority of the transarterial approach can be explained by the catheterization of a long stretch of complex arterial labyrinth. Therefore, it is not always possible to catheterize the nidus using an arterial approach. The significant effort required for arterial catheterization also explains why shorter intervention and fluoroscopy times were seen for the direct puncture technique [47]. It is imaginable that increasing availability of angiography systems with integrated cone beam $\mathrm{CT}$ technology will make the direct puncture technique more attractive, particularly because such systems are equipped with software-aided puncture tools. However, the preferred pathway for accessing T2ELs ultimately depends on the individual preference of the interventionalist.

\section{Local complications of T2EL embolization with $\mathrm{EVOH}$}

With respect to non-target embolization, the highly controllable flow behavior of EVOH is a clear advantage compared to NBCA. Nevertheless, it must be noted that extreme filling of the nidus with $\mathrm{EVOH}$ can result in an increase in pressure that is spontaneously released when the microcatheter is withdrawn from the T2EL, thereby resulting in non-targeted escape of not yet hardened EVOH into the periphery of a branch (e. g., AMI). In a current publication by Mozes et al., the EVOH-related complication rate was $4 \%$ ( $n=85$ patients) [26]. Local major complications of T2EL embolization with EVOH have only been described in individual cases [26, 42, 48-50]. Mesenteric and spinal ischemia as well as infection of the stent graft, psoas hematoma, abscess, spondylodiscitis, and damage to the lumbar plexus must be avoided. One case of pain-induced severe immediate vasovagal reaction with collapse probably caused by DMSO during embolization of a thoracic T2EL with EVOH was reported in a case report [51]. Moreover, direct puncture can result in extravasation of EVOH into the retroperitoneum $[17,48]$. To date, aortic rupture has not been described in the case of transarterial embolization or direct puncture [46].

\section{Conclusion}

In the case of T2EL persistence, aneurysm growth of $>5 \mathrm{~mm}$ in 6-12 months is an accepted indication for treatment. Many roads 
lead to Rome with respect to T2EL embolization. Transarterial angiographic access is usually selected with at least 4 alternative routes being considered. The goal is to direct the microcatheter into the nidus, which is not always possible given the generally difficult vessel anatomy. CT-guided direct puncture of the nidus with subsequent fluoroscopic embolization probably has better success rates. The treatment goal should always be complete T2EL embolization, ideally including the relevant branches. There is no ideal embolic agent for T2EL. Due to its excellent controllability, EVOH comes closest to meeting the requirements. It remains difficult to identify the embolization endpoint during intervention. An effective pressure reduction that prevents further growth of the aneurysm is decisive for lasting clinical success. Otherwise, subsequent interventions can be necessary. T2EL embolization is a challenge from A-Z, but the treatment has a low complication rate in the hands of experienced interventionalists.

\section{Conflict of Interest}

Prof. Dr. med. Claus Nolte-Ernsting has participated in an advisory board of the company Medtronic in 2018.

Private lecturer Dr. med. Alexander Stehr has performed consulting activities for the company Vascutek Terumo within the past 3 years.

\section{References}

[1] Rand T, Uberoi R, Cil B et al. Quality improvement guidelines for imaging detection and treatment of endoleaks following endovascular aneurysm repair (EVAR). Cardiovasc Intervent Radiol 2013; 36: 25-45

[2] Guo Q, Du X, Zhao J et al. Prevalence and risk factors of type II endoleaks after endovascular aneurysm repair: A meta-analysis. PLoS ONE 2017; 12: e0170600 doi:10.1371/journal.pone.0170600

[3] Sidloff DA, Gokani V, Stather PW et al. Type II endoleak: conservative management is a safe strategy. Eur J Vasc Endovasc Surg 2014; 48: 391399. doi:10.1016/j.ejvs.2014.06.035

[4] Ward T], Cohen S, Patel RS et al. Anatomic risk factors for type-2 endoleak following EVAR: A retrospective review of preoperative $\mathrm{CT}$ angiography in 326 patients. Cardiovasc Intervent Radiol 2014; 37: 324-328. doi:10.1007/s00270-013-0646-7

[5] Fukuda T, Matsuda $\mathrm{H}$, Sanda $\mathrm{Y}$ et al. CT findings of risk factors for persistent type II endoleak from inferior mesenteric artery to determine indicators of preoperative IMA embolization. Ann Vasc Dis 2014; 7: 274279. doi:10.3400/avd.oa.14-00008

[6] Löwenthal D, Herzog L, Rogits B et al. Identification of predictive CT angiographic factors in the developmenr of high-risk type 2 endoleaks after endovascular aneurysm repair in patients with infrarenal aortic aneurysms. Fortschr Röntgenstr 2015; 187: 49-55. doi:10.1055/ s-0034-1385123

[7] Seike Y, Matsuda H, Fukuda T et al. The influence of 4 or more patent lumbar arteries on persistent type II endoleak and sac expansion after endovascular aortic repair. Ann VAsc Surg 2018; 50: 195-201. doi:10.1016/j.avsg.2017.12.014

[8] Li B, Montbriand J, Eisenberg $\mathrm{N}$ et al. Pre-operative aneurysm thrombus volume, but not density, predicts type 2 endoleak rate following endovascular aneurysm repair. Ann Vasc Surg 2019; 57: 98-108. doi:10.1016| j.avsg.2018.09.012

[9] Arbeitsgemeinschaft der Wissenschaftlichen Medizinischen Fachgesellschaften (AWMF). S3-Leitlinie zu Screening, Diagnostik, Therapie und Nachsorge des Bauchaortenaneurysmas. 07.07.2018. https://www. awmf.org/leitlinien/detail/I/004-014.html
[10] Chaikof EL, Dalman RL, Eskandari MK. The Society for Vascular Surgery practice guidelines on the care of patients with an abdominal aortic aneurysm. J Vasc Surg 2018; 67: 2-77.e2. doi:10.1016/j.jvs.2017.10.044

[11] Wanhainen A, Verzini F, Van Herzeele I et al. European Society for Vascular Surgery (ESVS) 2019 Clinical Practice Guidelines on the Management of Abdominal Aorto-iliac Artery Aneurysms. Eur J Vasc Endovasc Surg 2019; 57: 8-93. doi:10.1016/j.ejvs.2018.09.020

[12] Jones JE, Atkins MD, Brewster DC et al. Persistent type 2 endoleak after endovascular repair of abdominal aortic aneurysm is associated with adverse late outcomes. J Vasc Surg 2007; 46: 1-8. doi:10.1016/ j.jvs.2007.02.073

[13] Dudeck O, Schnappauff D, Herzog L et al. Can early computed tomography angiography after endovascular aortic aneurysm repair predict the need for reintervention in patients with type II endoleak? Cardiovasc Intervent Radiol 2015; 38: 45-52. doi:10.1007/s00270-014-0901-6

[14] Chung R, Morgan RA. Type 2 endoleaks post-EVAR: current evidence for rupture risk, intervention ans outcomes of treatment. Cardiovasc Intervent Radiol 2015; 38: 507-522. doi:10.1007/s00270-014-0987-x

[15] Dingemans SA, Jonker FHW, Moll FL et al. Aneurysm sac enlargement after endovascular abdominal aortic aneurysm repair. Ann Vasc Surg 2016; 31: 229-238. doi:10.1016/j.avsg.2015.08.011

[16] Moulakakis KG, Klonaris C, Kakisis J et al. Treatment of Type II Endoleak and Aneurysm Expansion after EVAR. Ann Vasc Surg 2017; 39: 56-66. doi:10.1016/j.avsg.2016.08.029

[17] Marcelin C, le Bras Y, Petipierre F et al. Safety and efficacy of embolization using Onyx of persistent type II Endoleaks after abdominal endovascular aneurysm repair. Diagn Interv Imaging 2017; 98: 491-497. doi:10.1016/j.diii.2017.01.003

[18] Pineda DM, Calligaro KD, Tyagi S et al. Late type II Endoleaks after endovascular aneurysm repair require intervention more frequently than early type II Endoleaks. J Vasc Surg 2018; 67: 449-452. doi:10.1016/ j.jvs.2017.05.124

[19] Powell JT, Sweeting M], Ulug P. Meta-analysis of individual-patient data from EVAR-1, DREAM, OVER and ACE trials comparing outcomes of endovascular or open repair for abdominal aortic aneurysm over 5 years. Br J Surg 2017; 104: 166-178. doi:10.1002/bjs. 10430

[20] Solis MM, Ayerdi ], Babcock GA et al. Mechanism of failure in the treatment of type II Endoleak with percutaneous coil embolization. J Vasc Surg 2002; 36: 485-491. doi:10.1067/mva.2002.126542

[21] Abularrage C], Patel VI, Conrad MF et al. Improved results using Onyx glue for the treatment of persistent type 2 endoleak after endovascular aneurysm repair. J Vasc Surg 2012; 56: 630-636. doi:10.1016/j.jvs.2012.02.038

[22] Horinouchi H, Okada T, Yamaguchi M et al. Mid-term outcomes and predictors of transarterial embolization for type II Endoleak after endovascular abdominal aortic aneurysm repair. Cardiovasc Intervent Radiol 2020; 43: 696-705. doi:10.1007//s00270-020-02436-2

[23] Loy LM, Chua JME, Chong TT et al. Type 2 endoleaks: common and hard to eradicate yet benign? Cardiovasc Intervent Radiol 2020; 43: 963-970. doi:10.1007/s00270-020-02497-3

[24] Jamieson RW, Bachoo P, Tambyraja AL. Evidence for ethylene-vinyl-alcohol-copolymer liquid embolic agent as a monotherapy in treatment of Endoleaks. Eur J Vasc Endovasc Surg 2016; 51: 810-814. doi:10.1016/ j.ejvs.2016.02.015

[25] Torikai H, Inoue M, Nakatsuka S et al. Imaging findings of atypical type II endoleak through vasa vasorum after abdominal endovascular aneurysm repair. Cardiovasc Intervent Radiol 2018; 41: 186-190. doi:10.1007/s00270-017-1778-y

[26] Mozes GD, Pather K, Oderich GS et al. Outcomes of Onyx embolization of type II endoleaks after endovascular repair of abdominal aortic aneurysms. Ann Vasc Surg 2020; 67: 223-231. doi:10.1016/j. avsg.2020.02.013

[27] Müller-Wille R, Wohlgemuth WA, Heiss P et al. Transarterial embolization of type II endoleaks after EVAR: the role of ethylene vinyl alcohol 
copolymer (Onyx). Cardiovasc Intervent Radiol 2013; 36: 1288-1295. doi:10.1007/s00270-013-0567-5

[28] Guimaraes M, Wooster M. Onyx (ethylene-vinyl alcohol copolymer) in peripheral applications. Semin Intervent Radiol 2011; 28: 350-356. doi:10.1055/s-0031-1284462

[29] Wohlgemuth WA, Uller W, Müller-Wille R. Flüssigembolisate - Onyx als Problemlöser. Radiologe 2013; 53: 223-229. doi:10.1007/s00117-0122421-1

[30] Treitl KM, Scherr M, Förth M et al. Reduction of CT beam hardening artefacts of ethylene vinyl alcohol copolymer by variation of the tantalum content: evaluation in a standardized aortic endoleak phantom. Eur Radiol 2015; 25: 597-605. doi:10.1007/s00330-014-3438-9

[31] Pitton MB. Diagnosis and management of endoleaks after endovascular aneurysm repair: role of MRI. Abdom Imaging 2006; 31: 339-346. doi:10.1007/s00261-005-0370-0

[32] Harky A, Zywicka E, Santor G et al. Is contrast-enhanced ultrasound (CEUS) superior to computed tomography angiography (CTA) in detection of endoleaks in post-EVAR patients? A systematic review and metaanalysis. J Ultrasound 2019; 22: 65-75. doi:10.1007/s40477-01900364-7

[33] Binkert CA, Alencar H, Singh J et al. Translumbar type II endoleak repair using angiographic CT. J Vasc Intervent Radiol 2006; 17: 1349-1353. doi:10.1097/01.RVI.0000231966.74734.7D

[34] Wacker FK, Valdeig S, Raatschen HJ. C-arm CT - an adjunct to DSA for endoleak classification in patients with endovascular repair of abdominal aortic aneurysms. Fortschr Röntgenstr 2014; 186: 247-252. doi:10.1055/s-0033-1350500

[35] Mansueto G, Cenzi D, D'Onofrio M et al. Treatment of type II endoleaks after endovascular repair of abdominal aortic aneurysms: transcaval approach. Cardiovasc Intervent Radiol 2005; 28: 641-645. doi:10.1007| s00270-004-0328-6

[36] Scali ST, Vlada A, Chang CK et al. Transcaval embolization as an alternative technique for the treatment of type II endoleak after endovascular aortic aneurysm repair. J Vasc Surg 2013; 57: 869-874. doi:10.1016/ j.jvs.2012.09.021

[37] Hyatt E, McLaughlin JN, Shah $\mathrm{H}$ et al. Transcaval approach for embolization of type II Endoleak following endovascular aortic aneurysm repair. CVIR Endovasc 2019; 2: 3 doi:10.1186/s42155-018-0047-8

[38] Ameli-Renani S, Pavlidis V, Mailli L et al. Transiliac Paraendograft Embolisation of Type 2 Endoleak: An Alternative Approach for Endoleak Management. Cardiovasc Intervent Radiol 2016; 39: 279-283. doi:10.1007| s00270-015-1203-3

[39] Mewissen MW, Jan MF, Kuten D et al. Laser-Assisted Transgraft Embolization: A Technique for the Treatment of Type II Endoleaks. J Vasc Interv Radiol 2017; 28: 1600-1603. doi:10.1016/j.jvir.2017.07.029
[40] Ogawa Y, Hamaguchi S, Nishimaki $\mathrm{H}$ et al. Embolization by Direct Puncture with a Transpedicular Approach Using an Isocenter Puncture (ISOP) Method in a Patient with a Type II Endoleak After Endovascular Aortic Repair (EVAR). Cardiovasc Intervent Radiol 2015; 38: 731-735. doi:10.1007/s00270-015-1065-8

[41] Massis K, Carson WG 3rd, Rozas A. Treatment of type II endoleaks with ethylene-vinyl-alcohol copolymer (Onyx). Vasc Endovascular Surg 2012; 46: 251-257. doi:10.1177/1538574412442401

[42] Ford CA, Lange BB, Morris CS. Transcatheter embolization of abdominal aortic endograft Endoleaks using onyx and coils: mid-term imaging follow-up. Journal of Vascular Diagnostics and Interventions 2017; 5: 15-19

[43] Wojtaszek M, Wnuk E, Maciag R et al. Improving the results of transarterial embolization of type 2 endoleaks with the embolic polymer Onyx. Wideochir Inne Tech Maloinwazyjne 2016; 11: 259-267. doi:10.5114/ wiitm.2016.64747

[44] Aziz A, Menias CO, Sanchez LA et al. Outcomes of percutaneous endovascular intervention for type II endoleak with aneurysm expansion. J Vasc Surg 2012; 55: 1263-1267. doi:10.1016/j.jvs2011.10.131

[45] Madigan MC, Singh MJ, Chaer RA et al. Occult type I or III endoleaks are a common cause of failure of type II endoleak treatment after endovascular aortic repair. J Vasc Surg 2019; 69: 432-439. doi:10.1016| j.jvs.2018.04.054

[46] Guo Q, Zhao J, Ma Y et al. A meta-analysis of translumbar embolization versus transarterial embolization for type II endoleak after endovascular repair of abdominal aortic aneurysm. J Vasc Surg 2020; 71: 1029-1034. e1. doi:10.1016/j.jvs.2019.05.074

[47] Yang RY, Tan KT, Beecroft JR et al. Direct sac puncture versus transarterial embolization of type II endoleaks: An evaluation and comparison of outcomes. Vascular 2017; 25: 227-233. doi:10.1177| 1708538116663992

[48] Khaja MS, Park AW, Swee W et al. Treatment of type II endoleak using Onyx with long-term imaging follow-up. Cardiovasc Intervent Radiol 2014; 37: 613-622. doi:10.1007/s00270-013-0706-z

[49] Sella DM, Frey GT, Giesbrandt K. Osteomyelitis and Discitis Following Translumbar Repair of a Type II Endoleak. Cardiovasc Intervent Radiol 2016; 39: 458-461. doi:10.1007/s00270-015-1229-6

[50] Das Gupta J, Rana MA, McGrew P et al. Ischemic lumbosacral plexopathy after extensive Onyx arterial embolization for type 2 endoleak. J Vasc Interv Radiol 2019; 30: 619-621. doi:10.1016/j.jvir.2018.09.025

[51] Wildgruber M, Müller-Wille R, Busch V et al. Severe adverse reaction during DMSO injection for Onyx embolization of a thoracic type II endoleak. Cardiovasc Intervent Radiol 2016; 39: 144-145. doi:10.1007| s00270-015-1187-z 